\title{
Pra Desain Pabrik Hexamethylene Tetramine dari Formaldehid dan Ammonia Menggunakan Proses Meissner dengan Kapasitas Produksi 7000 Ton
}

\author{
Nurul Maziyah, Laila Nur Rahmah, dan Arief Widjaja \\ Teknik Kimia, Fakultas Teknologi Industri, Institut Teknologi Sepuluh Nopember (ITS) \\ Jl. Arief Rahman Hakim, Surabaya 60111 Indonesia \\ e-mail: arief_w@chem-eng.its.ac.id
}

\begin{abstract}
Abstrak-Hexamethylene Tetramine (HMTA) atau yang lebih dikenal dengan hexamine memiliki penggunaan yang luas di bidang industri kimia yaitu sebagai akselerator pada industri karet, campuran TNT pada industri bahan peledak, shrinkproofing agent untuk memperindah warna pada industri tekstil, bahan pelapis butiran pupuk urea, inhibitor korosi, curing agent pada industri resin, bahan baku antiseptik, serta industri serat selulosa. Selain itu, dalam jumlah rendah, hexamine juga digunakan pada sintesis glycine maupun sebagai stabilizer pada polyvinyl acetate dan pelarut pada ekstraksi fenol. Indonesia sendiri hanya memiliki dua industri untuk memproduksi hexamine dan belum cukup untuk memenuhi kebutuhan sehingga Indonesia masih harus impor. Padahal kebutuhan hexamine terus meningkat dari tahun ketahun. Menurut BPS (2004 - 2011), impor hexamine Indonesia pada tahun 2011 mencapai $13.227 .201 \mathrm{~kg}$. Melihat banyaknya kegunaan hexamine dalam berbagai bidang dan perkembangan industri di Indonesia yang memanfaatkan produk ini sebagai bahan baku, maka pendirian pabrik ini sangat dibutuhkan. Pabrik Hexamethylene Tetramine direncanakan berdiri pada tahun 2019 yang berlokasi di Palembang, Sumatera Selatan dengan kapasitas produksi sebesar 7000 ton/tahun. Proses yang digunakan pada perencanaan Pabrik Hexamethylene Tetramine ini adalah menggunakan proses Meissner. Proses pembuatan hexamine dengan proses ini dapat dibagi dalam beberapa tahap, antara lain tahap persiapan bahan baku yakni ammonia dan formaldehid, tahap pembentukan hexamine di dalam reaktor yang selanjutnya diproses lebih lanjut untuk memisahkan kristal hexamine yang telah terbentuk, dan tahap pemurnian dan penyimpanan produk. Pabrik Hexamethylene Tetramine ini direncanakan beroperasi secara kontinyu selama 24 jam dengan waktu produksi 330 hari/tahun. Berdasarkan analisa ekonomi yang telah dilakukan diperoleh internal rate of return sebesar 19,05\% dengan pay out time selama 4,9 tahun dan break even point sebesar $40 \%$. Ditinjau dari uraian di atas, maka secara teknis dan ekonomis, pabrik Hexamethylene Tetramine dari ammonia dan formaldehid layak untuk didirikan.
\end{abstract}

Kata Kunci-Hexamethylene Tetramine, ammonia, formaldehid, Meissner

\section{PENDAHULUAN}

$\mathrm{P}$ ERKEMBANGAN industri di Indonesia akhir-akhir ini mengalami peningkatan yang cukup signifikan. Peningkatan terjadi di semua industri terutama yang bersifat padat modal dan berteknologi tinggi. Peningkatan ini diharapkan lebih memacu persaingan Indonesia dengan negaranegara maju lainnya.

Diantara semua jenis industri, industri kimia menjadi salah satu industri yang peningkatan perkembangannya terjadi dengan baik. Industri kimia ini umumnya menghasilkan produk berupa bahan baku bagi industri hilir atau bisa dikatakan sebagai industri pemakainya. Untuk itu, industri kimia diharapkan memegang peranan penting dalam penguatan dan pendalaman struktur industri, terutama yang berbasis pada pengolahan sumber daya alam sehingga memperkukuh keterkaitan antara industri hulu dengan industri hilir maupun antara sektor industri dengan sektor ekonomi lainnya

Dilihat secara umum industri kimia menunjukan proses kenaikan dikarenakan adanya perluasan kapasitas produksi beberapa pabrik dan pembangunan pabrik-pabrik kimia baru serta makin meningkatnya permintaan pasar terutama pasar ekspor. Peningkatan yang pesat ini selain didorong oleh meningkatnya permintaan ekspor sehingga beberapa pabrik melakukan perluasan kapasitas produksi, juga dikarenakan bertambahnya permohonan investasi baru untuk pembangunan pabrik-pabrik kimia hulu.

Hexamethylene Tetramine atau biasa disebut sebagai hexamine merupakan salah satu produk industri kimia yang sangat penting bagi kehidupan. Selama Perang Dunia ke II bahan ini banyak digunakan sebagai bahan baku pembuatan cyclonite yang mempunyai daya ledak sangat tinggi. Setelah masa perang usai, bahan peledak ini masih diperlukan untuk keperluan pertahanan dan keamanan dan industri pertambangan. Hexamine banyak digunakan juga dalam berbagai bidang antara lain: bidang kedokteran (bahan baku antiseptik), industri resin (curing agent), industri karet (accelerator yaitu agar karet menjadi elastis), industri tekstil (shrink-proofing agent dan untuk memperindah warna), industri serat selulosa (menambah elastisitas), dan pada industri buah digunakan sebagai fungisida pada tanaman jeruk untuk menjaga tanaman dari serangan jamur. [1]

Sampai saat ini, untuk memenuhi kebutuhan Hexamine di Indonesia masih mengandalkan impor dari luar. Padahal kebutuhan Hexamine sendiri dari tahun ke tahun semakin bertambah. Untuk memenuhi kebutuhan hexamine tersebut, Indonesia harus mengimpor Hexamine dengan skala cukup besar. Hal ini dapat diketahui dari data ekspor-impor hexamine di Indonesia dari Badan Pusat Statistik yang terdapat pada tabel 
1. [2]

Tabel 1. Data ekspor-impor Hexamethylene Tetramine di Indonesia

\begin{tabular}{ccc}
\hline \hline Tahun & Ekspor $(\mathrm{kg})$ & Impor $(\mathrm{kg})$ \\
\hline 2008 & 0 & 11.887 .901 \\
2009 & 0 & 9.649 .391 \\
2010 & 0 & 12.934 .947 \\
2011 & 0 & 13.227 .201 \\
\hline
\end{tabular}

Sesuai data yang didapat dari 1, dapat disimpulkan bahwa kebutuhan Hexamine di Indonesia terus bertambah. Hal ini diketahui dari kecenderungan impor yang terus meningkat dari tahun 2008 hingga 2011, walaupun pada tahun 2009 impor Hexamine mengalami penurunan. Selain itu, hingga tahun 2011 Indonesia belum dapat bersaing di tingkat internasional dalam hal pemenuhan kebutuhan hexamine dunia karena Indonesia masih belum mampu untuk mengekspor produk ini.

Melihat belum terpenuhinya kebutuhan akan hexamine sementara itu banyak kegunaan hexamine dalam berbagai bidang dan perkembangan industri di Indonesia yang memanfaatkan produk ini sebagai bahan baku, maka pendirian pabrik ini sangat dibutuhkan.

\section{SELEKSI DAN URAIAN PROSES}

\section{A. Seleksi Proses}

Sampai saat ini ada 2 jenis proses yang paling banyak digunakan pada pembuatan Hexamethylene Tetramine yaitu proses Leonard dan proses Meissner. Proses Leonard menggunakan reaksi dengan fase cair. Bahan baku yang digunakan adalah larutan ammonia dan larutan formaldehid. Larutan formaldehid 37\% direaksikan dengan larutan ammonia berlebih untuk membentuk hexamine dan air secara eksotermis. Reaksi yang terjadi adalah sebagai berikut:

$6 \mathrm{CH} 2 \mathrm{O}(\mathrm{l})+4 \mathrm{NH} 3(\mathrm{l}) \rightarrow \mathrm{C} 6 \mathrm{H} 12 \mathrm{~N} 4(\mathrm{l})+6 \mathrm{H} 2 \mathrm{O}(\mathrm{l})+81 \mathrm{kcal} / \mathrm{mol}$

Proses dibagi dalam beberapa tahapan seperti reaksi kondensasi antara formaldehid dan ammonia, penguapan hexamine, pemekatan, dan penyaringan. Reaksi diawali dengan proses penyaringan gas ammonia dan mencampurkannya dengan larutan formaldehid secara ekses (0.8-1.2\%,). Lalu proses dilanjutkan dengan mengirim campuran tersebut ke tangki reaktor untuk proses reaksi. Yield yang didapatkan sebesar 24-27\% larutan hexamine. Panas dari reaksi ditransfer keluar dengan mensirkulasi air pendingin untuk menjaga suhu reaksi pada suhu $60-65^{\circ} \mathrm{C}$. Selanjutnya larutan hexamine yang terbentuk dipompa ke evaporator dalam kondisi vakum untuk proses pemekatan sehingga konsentrasi menjadi 60-65 \%.

Proses dilanjutkan dengan pemekatan dan dehidrasi dari larutan hexamine 60-65 \% di evaporator kedua. Di dalam evaporator terjadi penguapan sisa-sisa reaktan dan mulai terjadi proses pengkristalan. Produk keluar evaporator kemudian dimasukkan ke dalam centrifuge dan dikeringkan di dryer, setelah itu produk kemudian dikemas. Dengan proses ini dapat diperoleh yield overall sebesar $95-96 \%$ berdasarkan reaktan formalin. [1]

Kekurangan dari proses ini adalah proses produksi membutuhkan steam dan konsumsi listrik lebih banyak serta produk yang dihasilkan juga kurang optimal. Air limbah yang dihasilkan dari proses produksi lebih tinggi jika dibandingkan dengan proses yang lain. Penggunaan larutan formaldehid dan operasi secara batch dapat menghasilkan impuritis dan reaksi samping, dari kedua dampak tersebut dapat mengakibatkan efek negatif terhadap kemurnian produk.

Pada proses Meissner larutan formaldehid dan gas ammonia dicampurkan ke dalam tangki reaktor mengalami reaksi di dalam larutan alkali. Reaksi yang terjadi adalah sebagai berikut: $6 \mathrm{CH} 2 \mathrm{O}(\mathrm{l})+4 \mathrm{NH}(\mathrm{gas}) \rightarrow(\mathrm{CH} 2) 6 \mathrm{~N} 4(\mathrm{l})+6 \mathrm{H} 2 \mathrm{O}(\mathrm{l})+745.29 \times 103 \mathrm{Kcal} / \mathrm{mol}$

Formaldehid dialirkan dari tangki Formaldehid masuk ke dalam reaktor bersama Ammonia. Reaksi yang terjadi sangat cepat sehingga yang mengontrol kecepatan reaksi adalah kecepatan pembentukan kristal hexamine. Pada proses ini panas reaksi yang terjadi pada reaktor digunakan untuk menguapkan air hasil reaksi. Untuk menjaga suhu reaksi digunakan gas inert atau pun dengan pengaturan tekanan total saat campuran dalam reaktor mendidih. Hal ini untuk mengurangi kebutuhan pendingin. Waktu reaksi pada reaktor 15-30 menit. Uap dalam reaktor dikondensasikan sedangkan bahan inert serta impuritas seperti methanol dibuang dari bagian atas reaktor sebagai limbah gas. Limbah gas ini masih mengandung hidrogen 18 $20 \%$ dan dapat dimanfaatkan sebagai bahan bakar. [3]

Tabel 2 menunjukkan perbandingan antara proses Leonard dan proses Meissner berdasarkan per ton formalin yang digunakan.

Tabel 2. Data perbandingan proses Leonard dan Meissner

\begin{tabular}{ccc}
\hline \multirow{2}{*}{ Parameter } & \multicolumn{2}{c}{ Macam Proses } \\
& Leonard & Meissner \\
\hline \multirow{2}{*}{ Bahan Baku } & Larutan & Formaldehid \\
& Larutan Amonia & Farutan \\
Formaldehid \\
Gas Amonia \\
Amonia & $540-550 \mathrm{~kg}$ & $530 \mathrm{~kg}$ \\
Formaldehid & $3,5-3,6$ ton & 3,5 ton \\
Konversi & $96 \%$ & $97 \%$ \\
Steam & $4,0-5,0$ & $0,5-1,0$ \\
Daya listrik & $200 \mathrm{Kwh}$ & $300 \mathrm{Kwh}$ \\
Air & 300 ton & 150 ton \\
Tekanan & Vakum & Vakum \\
Suhu & $30^{\circ} \mathrm{C}-50^{\circ} \mathrm{C}$ & $50^{\circ} \mathrm{C}-80^{\circ} \mathrm{C}$ \\
\hline \hline
\end{tabular}

Berdasarkan pada Tabel 2, proses dengan proses Meissner merupakan proses yang lebih baik daripada proses Leonard karena menghasilkan konversi yang lebih besar yakni konversi 97\%. Dan apabila dibandingkan dengan proses Leonard proses Meissner memerlukan bahan baku yang lebih effisien. Maka dari itu rancangan pabrik hexamine menggunakan proses Meissner.

\section{B. Tahap Persiapan Bahan Baku}

Bahan baku yang digunakan dalam perencanaan pabrik Hexamethylene Tetramine ini adalah ammonia dan formaldehid. Proses Meissner merupakan reaksi yang dilakukan pada fase gas. Ammonia disimpan dalam keadaan liquid pada tangki penyimpan ammonia (F-113) pada suhu $33^{\circ} \mathrm{C}$. Dari tangki penyimpan dialirkan ke vaporizer $(\mathrm{V}-115)$ untuk merubah fase ammonia dari liquid menjadi gas serta untuk membuat tekanannya turun menjadi 1 atm pada suhu $30^{\circ} \mathrm{C}$. Kemudian ammonia dialirkan ke dalam reaktor. Pada proses ini sumber gas formaldehid berasal dari reaksi oksidasi methanol dengan udara yang kemudian disimpan di tangki penyimpanan (F-111). Gas formaldehid tersebut langsung dialirkan bersamaan dengan gas ammonia ke dalam tangki reaktor.[4] 


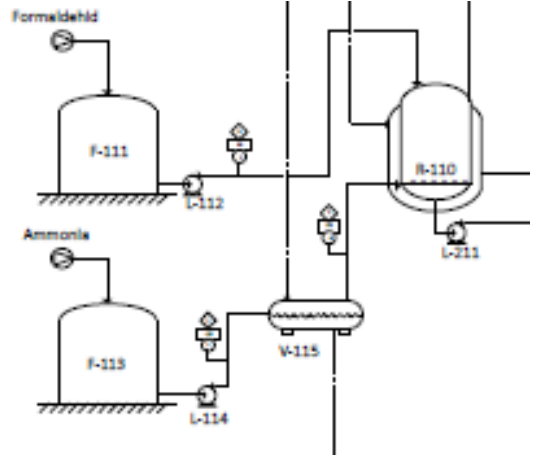

Gambar 1. Tahap Persiapan Bahan Baku

\section{Tahap Pembentukan Hexamine}

Formaldehid dialirkan dari tangki formaldehid masuk ke dalam reaktor (R-110) bersama ammonia. Reaktor yang digunakan adalah bubble column reactor berupa silinder tegak dengan tutup atas dan tutup bawah berbentuk standard dished head. Tangki reaktor alir beroperasi pada suhu $80{ }^{\circ} \mathrm{C}$ dan tekanan $1 \mathrm{~atm}$. Reaktor dilengkapi dengan jaket dikarenakan reaksi yang terjadi adalah eksotermik sehingga diperlukan pendingin untuk menjaga temperatur, serta sparger untuk mempermudah kontak reaksi antara ammonia dan formaldehid. [5] Kedua bahan baku diumpankan dalam reaktor dengan perbandingan mol formaldehid : ammonia $=3: 2$ pada keadaan eksotermik dengan konversi sebesar 97\%. Reaksi pembentukan hexamine sebagai berikut :

$$
4 \mathrm{NH} 3+6 \mathrm{CH} 2 \mathrm{O} \rightarrow \mathrm{C} 6 \mathrm{H} 12 \mathrm{~N} 4+6 \mathrm{H} 2 \mathrm{O}, \Delta \mathrm{H}=-230 \mathrm{~kJ} / \mathrm{mol}
$$

Hasil reaksi dari reaktor berupa larutan hexamine dialirkan masuk ke dalam evaporator (V-210) menggunakan pompa (L211) untuk dipekatkan konsentrasinya. Evaporator beroperasi pada suhu $101 \mathrm{oC}$ dan tekanan vakum. Evaporator yang digunakan adalah short tube evaporator yang dilengkapi dengan barometric condenser (H-212), steam jet ejector (G-214) dan hot well (F-213) untuk mempertahankan evaporator dalam kondisi vakum. Kepekatan larutan hexamine keluaran dari evaporator ini sebesar 55\%. [6]

Larutan pekat dari evaporator dialirkan dengan pompa (L221) ke crystallizer (X-220) agar terbentuk inti kristal di larutan tersebut. Crystallizer yang digunakan adalah jenis swenson walker crystallizer. Kristal hexamine yang terbentuk $90 \%$ dari aliran yang masuk ke crystallizer. Selanjutnya larutan yang telah terbentuk kristal tersebut dialirkan ke centrifuge $(\mathrm{H}-230)$ untuk dipisahkan antara kristal Hexamine dengan larutan induknya (mother liquor). Centrifuge yang digunakan berjenis hellical conveyor. Recycle dari centrifuge sebesar 10\%. Larutan yang keluar centrifuge (mother liquor) kemudian di-recycle kembali menuju crystallizer (X-220) menggunakan pompa (L231). Sedangkan kristal hexamine yang keluar dari centrifuge (H-230) dialirkan dengan conveyor (J-311) untuk dikeringkan menggunakan rotary dryer (B-310). [6]

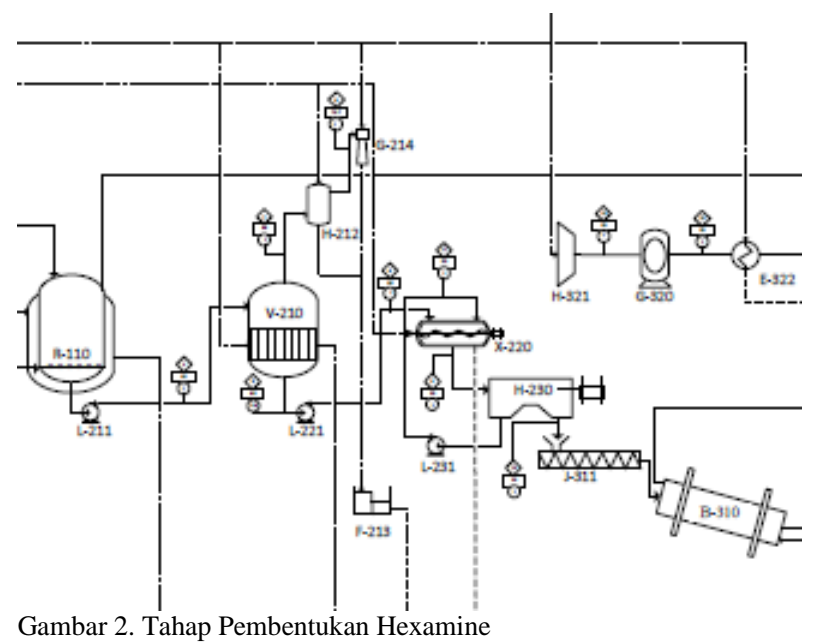

\section{Tahap Pemurnian dan Penyimpanan Produk}

Kristal hexamine kemudian dikeringkan di rotary dryer (B310) hingga kadar air terkandung dalam hexamine mencapai konsentrasi produk yang diharapkan yaitu 99\%. Udara kering di rotary dryer didapatkan dari udara luar yang telah melewati filter udara (H-321) kemudian dialirkan ke rotary dryer menggunakan blower (G-320) dan akan dinaikkan suhunya dengan heater (E-322) sebelum memasuki rotary dryer. Debu yang terbawa dalam udara keluaran dari rotary dryer akan masuk ke dalam cyclone (H-323) untuk dipisahkan antara debu dan udara. Kemudian debu dialirkan ke dalam ball mill (C314) untuk mengurangi losses dari Hexamine.

Kristal hexamine dari rotary dryer selanjutnya dihancurkan pada ball mill (C-314) dan diseragamkan ukurannya melalui screen (H-315) sampai berukuran 200 mesh (kurang lebih 0.1 $\mathrm{mm}$ ). Kristal hexamine yang masih berukuran besar dan tidak dapat melewati screen akan dikembalikan ke ball mill menggunakan bucket elevator (J-316) untuk dihancurkan kembali. Kristal yang telah sesuai standar ditampung di silo (F317) sebagai produk Hexametylene Tetramine.[6]

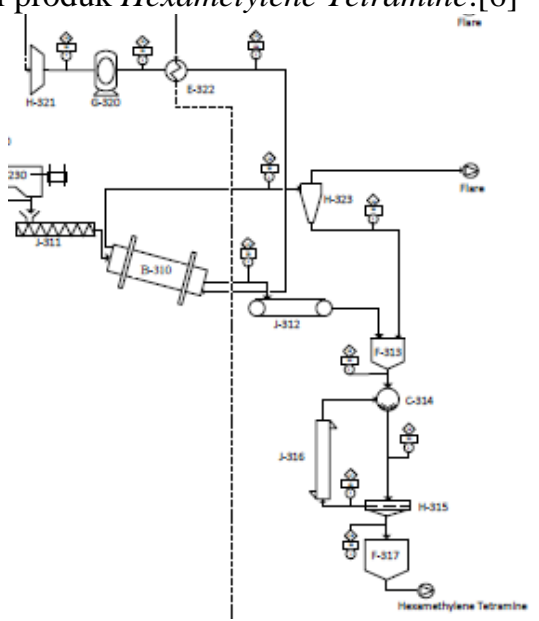

Gambar 3. Tahap Pemurnian dan Penyimpanan Produk 
Dari perhitungan material balance dengan operasi pabrik 330 hari/tahun dan 24 jam/hari dengan basis waktu 1 jam, kebutuhan ammonia adalah sebesar 440,5 kg/jam dan formaldehid sebesar $3133,2 \mathrm{~kg} / \mathrm{jam}$. Dan hexamine yang dihasilkan sebesar 883,838 kg/jam.

\section{ANALISA EKONOMI}

Pabrik Hexamine direncanakan memiliki 60 orang pekerja dengan komposisi modal 30\% modal sendiri dan $70 \%$ modal pinjaman dan bunga bank 10,25\%. Dari hasil perhitungan pada neraca ekonomi didapatkan biaya produksi total $\mathrm{Rp}$ 205.131.935.200,00. Selain itu, diperoleh IRR sebesar 19,05\% dan Break Even Point sebesar $40 \%$ dimana pengembalian modalnya selama 4,9 tahun. Umur dari pabrik ini diperkirakan selama 10 tahun dengan masa periode pembangunannya selama 2 tahun dengan operasi pabrik ini 330 hari/tahun.[7]

\section{KESIMPULAN/RINGKASAN}

Berdasarkan analisa ekonomi dengan metode discounted cash flow terhadap faktor ekonomi pra desain pabrik bioetanol dari nira siwalan ini, maka diperoleh hasil sebagai berikut :

1. Laju Pengembalian Modal (Rate Of Return) sebesar 19,05 $\%$ per tahun. Hal ini menunjukkan bahwa ROR yang diperoleh lebih besar dibandingkan dengan nilai i untuk pinjaman modal pada bank dengan tingkat bunga $10 \%$ per tahun sehingga pabrik layak didirikan.

2. Waktu pengembalian modal (Pay Out Time) pabrik ini adalah 4,9 tahun

3. Titik impas (Break Even Point) adalah $40 \%$

Dari hasil evaluasi secara teknis dan ekonomis, pabrik Hexamethylene Tetramine dari ammonia dan formaldehid ini sudah memenuhi syarat untuk dilanjutkan ke tingkat perencanaan. Dari segi ekonomi, pra rencana ini telah layak didirikan dengan masa konstruksi 2 tahun dan umur pabrik 10 tahun.

\section{UCAPAN TERIMA KASIH}

Penulis mengucapkan terima kasih kepada Bapak Prof. Dr. Ir. Arief Widjaja, M.Eng selaku dosen pembimbing dan seluruh crew Laboratorium Teknologi Biokimia Teknik Kimia FTIITS.

\section{DAFTAR PUSTAKA}

[1] Kent, J.A, "Handbook of Industrial Chemistry and Biotechnology", $12^{\text {th }}$ edition, New York: Springer Science Business Media. (2012)

[2] Badan Pusat Statistik

[3] European Patent Office no. 0468353b

[4] Geankoplis, Christie John." Transport Processes And separation process principles, 4th edition. Prentie Hall of India, New Delhi (2003).

[5] Levenspiel, Octave, "Chemical Reaction Engineering", 3rd ed., John Willey and Sons Inc., Singapore, (1999)

[6] Perry, Robert H. and Don Green. "Perry's Chemical Engineer's Handbook, 7th Edition". Mc Graw Hill Book Company, New York, (1997)

[7] Klaus. D. Timmerhaus and Ronald. E.W, "Plant Design and Economics for Chemical Engineering", 4th International Edition McGraw Hill Book, (1991) 